\title{
HACIA UNA CARACTERIZACIÓN DE LOS TEXTOS MULTIMODALES USADOS EN FORMACIÓN INICIAL DOCENTE EN LENGUAJE Y COMUNICACIÓN*
}

\author{
Miguel Farías Farías** \\ Claudio Araya Seguel ${ }^{* * *}$
}

\section{Resumen}

En el contexto de lectura del texto multimodal en formación inicial docente en Lenguaje y Comunicación, se informa de una investigación que caracteriza los tipos de textos, procedimientos y estrategias lectoras de estudiantes en sus trayectos lectores desde el papel a la pantalla y describe los enfoques de metodólogos. Se aplicaron dos encuestas a 61 estudiantes y 5 metodólogos. Los hallazgos señalan que los estudiantes mayoritariamente leen textos literarios e impresos, acceden a internet para labores cotidianas y académicas, tienen Facebook y leen textos digitales; leen textos con imágenes en pantalla. Con diferencias generacionales, los metodólogos muestran una leve aceptación del texto multimodal, pero también un énfasis en el texto literario impreso.

Palabras clave: texto multimodal, formación inicial, comprensión lectora, metodología de la lectura.

\section{TOWARDS A CHARACTERIZATION OF MULTIMODAL TEXTS USED IN LANGUAGE AND COMMUNICATION PRE-SERVICE TEACHER EDUCATION}

\begin{abstract}
In the context of multimodal reading in pre-service teacher education in Language and Communication, we report on a study that sought to characterize the types of texts, reading procedures and strategies used in students' transit from reading the page to the screen and to describe the methodologies used by educators. Two surveys were applied to 61 students and 5 educators. Findings indicate that most students read literary and other printed texts; they access virtual platforms for everyday and academic work, have a Facebook account, and read digital texts; they read texts containing images primarily on screen. With generational variations, teacher educators evidence a mild acceptance of multimodal texts, but also an emphasis on printed literary texts.
\end{abstract}

Key words: multimodal text, pre-service education, reading comprehension, approaches to reading.

Recibido: 18-04-2015

Aceptado: 05-05-2015

* Este trabajo es resultado parcial del proyecto DICYT 031351FF, Universidad de Santiago de Chile.

** Chileno, Ph. D., Departamento de Lingüística y Literatura, USACH, miguel.farias@usach.cl

*** Chileno, Magister en Lingüística, Departamento de Lingüística y Literatura, USACH. claurayas@ gmail.com 


\section{Introducción}

Pese a que el paso de la página a la pantalla es un fenómeno reconocido en la discusión de los procesos sociocognitivos asociados a la lectura, los modelos de comprensión lectora no dan cuenta a cabalidad de la participación de la dimensión visual en la lectura del texto multimodal (Kress y van Leuween, 2001). En este trabajo se informa de una etapa de un proyecto de investigación denominado "Alfabetización visual crítica en lengua materna: estrategias metacognitivas en la comprensión lectora de textos multimodales" en la cual se intenta caracterizar los textos usados por estudiantes en programas de formación inicial docente en Lenguaje y Comunicación y las estrategias pedagógicas en la didáctica de la lectura utilizados por metodólogos de cuatro universidades (dos tradicionales y dos privadas) de la Región Metropolitana en Santiago de Chile. Las preguntas que guían esta etapa de la investigación son: a) ¿qué exposición y uso de textos multimodales tienen los estudiantes en programas de formación inicial docente en Lenguaje y Comunicación?, y b) ¿Recibe el texto multimodal la debida atención en la didáctica de la lectura en esos programas? Para abordar la primera pregunta, se utilizó un cuestionario de 10 preguntas semi dirigidas y abiertas con el fin de recolectar datos sobre, entre otras cosas, cuáles son los rasgos semióticos de los textos usados tanto en la vida cotidiana como en los estudios universitarios. Para la segunda, se recogieron datos por medio de una encuesta semi dirigida aplicada a cinco profesores de la asignatura Didáctica (Metodología) en programas de formación docente en Pedagogía en Lenguaje y Comunicación de cuatro universidades de la RM con el fin de identificar y definir los focos de atención al momento de abordar pedagógicamente la comprensión lectora y el tratamiento del texto multimodal.

Estos antecedentes recabados permitirán, en una etapa posterior del proyecto, construir instrumentos de evaluación de la comprensión de lectura en lengua materna que considere diversos recursos semióticos en la articulación del discurso, lo que a su vez constituirá un aporte a los procesos de enseñanza aprendizaje de la literacidad hoy. Conceptualmente cabe señalar que usamos el término de literacidad en su acepción reciente como traducción del inglés literacy, que abarca un campo semántico más amplio que la palabra alfabetización dado que cubre competencias de sobrevivencia cívica y cultural que sobrepasan 
la mera habilidad de codificar y decodificar el nombre propio. En otros contextos del mundo hispanohablante también se usa lectoescritura, literacidad o escrituralidad (ver Hall et al., 2011 y Cassany, 2005 para una reseña etimológica y de uso de estos conceptos).

A continuación, en primer lugar se examinan algunos antecedentes entregados por algunas investigaciones desarrolladas en Chile en relación con los procesos sociocognitivos asociados a la lectura en distintos soportes y modos (Peronard, 2007; Del Valle et al., 2012; Pereira y González, 2011) que abordan, desde distintos enfoques, el problema del creciente uso de imágenes en los textos y la transición (donde la hay) de los trayectos lectores del soporte papel a la pantalla. En segundo lugar, se presentan los resultados de las dos encuestas y, por último, se esbozan algunas conclusiones a partir de los resultados y a la luz del marco conceptual reseñado.

\section{Antecedentes}

En una investigación desarrollada por Peronard (2007), cuyo principal objetivo era contrastar los niveles de comprensión y rapidez en la lectura de un mismo texto de carácter científico en soporte pantalla y papel en 158 estudiantes universitarios de primer año de seis carreras distintas, se concluye que -en general- los niveles de comprensión lectora independientemente del soporte son bajos. Además, la lectura en soporte papel se desarrolla de forma más rápida y la comprensión asociada a dicho soporte resulta mucho más eficiente en una prueba de aplicación. En esta misma línea, los estudiantes que leyeron inicialmente en papel, luego al enfrentar la lectura en pantalla evidenciaron mayores logros. Asimismo, la actitud mostrada por los estudiantes frente a la lectura en pantalla, según la investigadora, no determina mayormente los niveles de logro en la prueba de comprensión.

Resulta particularmente interesante -según la autora- que si bien la lectura en pantalla ofrece la posibilidad de mayor cantidad de información, lo cual hipotéticamente haría pensar en un proceso lector más eficiente, la lectura en papel sigue siendo más efectiva. En este sentido, podemos advertir que las conclusiones de este estudio reseñado no se alejan de las percepciones obtenidas al observar los resultados de nuestra encuesta. Al parecer, los estudiantes universitarios de diversas carreras, optan de manera preferente por la lectura en papel; mientras 
que la lectura en pantalla les resulta más compleja (quizás porque existen muchos elementos que generan distracción), lo que se podría explicar eventualmente por el tipo de instrucción en el ámbito de la comprensión lectora que reciben en su etapa escolar, la que prescinde de la integración de otros recursos de producción de significado distintos de la lengua. Este fenómeno en los procesos adaptativos desde la lectura (entendida como proceso global de construcción de significados) en soporte papel a la lectura en pantalla ya había sido anunciado en Turkle (1995). La autora, conocida como la gran sacerdotisa del ciberespacio, al referirse a la definición de Jameson del posmodernismo y la necesidad de encontrar un objeto que lo represente, argumenta que estos objetos serían los que se asocian al uso del computador. Estos objetos "existen en la información y las conexiones de Internet y World Wide Web, y en las ventanas, íconos y capas de la informática personal....Todos ellos son vida en la pantalla" (Turkle, 1995, p. 59). Al referirse a las capacidades de simulación del computador, la autora menciona que con los ordenadores podemos simular la naturaleza en un programa o dejar la naturaleza de lado y construir segundas naturalezas limitadas solo por nuestros poderes de imaginación y abstracción....la vida está en la pantalla sin orígenes ni fundamento. Es un lugar en que los signos tomados de la realidad sustituyen a los reales. Su estética tiene que ver con la manipulación y la recombinación (Turkle, 1995, p. 61).

Más aún, para los propósitos de este proyecto nos interesa plantearnos, de manera global, los cambios introducidos por las tecnologías de la información y las comunicaciones en el lenguaje y en las estructuras y procesos comunicacionales en este paso de la cultura impresa a lo que Luke (2000) denomina la cibertextualidad.

Ante este cambiante y, la vez, fluido panorama en las formas y representaciones de la comunicación, cabe preguntarse qué está sucediendo en el área de la formación de los docentes, pues la conclusión más lógica indica que (y los resultados de nuestra investigación lo corroboran) los profesores en formación emplean y valoran el texto lingüístico en papel y, a su vez, sus profesores emplean en sus clases textos de las mismas características.

Sin duda, estos resultados y conclusiones obtenidas se enmarcan en el ámbito de los procesos de lectura multimodal, lo que implica que recorremos un camino dirigido hacia la alfabetización visual y esta 
habilidad pasa en buena medida por la lectura de medios o alfabetización mediática (crítica, agregamos nosotros), como lo constatan Barragán y Gómez, 2012; Serafini, 2011; Unsworth, 2006; Buckingham, 2008, entre otros.

En este sentido, la investigación de Del Valle et al. (2012) desarrollada en el ámbito del acceso y consumo de los medios en estudiantes de pedagogía de diversas universidades de las zonas centro y sur de Chile, ratifica muchas de las observaciones desprendidas de los estudios anteriormente reseñados. No deja de llamar la atención que quienes están llamados a abordar el tema de la lectura crítica de medios, los profesores de Lenguaje, evidencien un escaso acercamiento, por ejemplo, a informarse a través de medios electrónicos lo cual -a su vez- podría ilustrar la predilección de ese grupo, por la lectura en soporte papel; a diferencia de los estudiantes de pedagogía en Historia, los que mostraron una mayor cercanía tanto al acceso y -sobre todo-al consumo de noticias en soportes de distinto tipo (Del Valle et al., 2012). Asimismo, en este estudio se concluye que se ha hecho el esfuerzo por incorporar el tema de los medios, pero sin examinarlos en cuando a la configuración semiótica y comunicativa que los articula. Incluso de esta investigación se desprende un perfil diferenciado en cuanto a carrera: los estudiantes de pedagogía en Historia parecen ser consumidores mucho más críticos de los medios, lo que se aprecia en su disposición y acceso a variadas posibilidades de acceso a la información; por su parte, los estudiantes de Pedagogía en Lenguaje, quienes -por lo demás- debieran estar preparados para enfrentar este cambio de enfoque centrado en la lectura crítica de medios, evidencian escasas herramientas críticas para comprender y mediar en la enseñanza y aprendizaje acerca del funcionamiento y efectos que los medios ejercen sobre la realidad (Del Valle et al., 2012), particularmente la televisión. Esto último sin duda reviste preocupación, pues además es relevante mencionar como descubrimiento de este estudio el que los estudiantes de Pedagogía en Lenguaje utilizan de forma menor la Internet para informarse sobre temas de actualidad, a diferencia de lo que ocurre con los estudiantes de Pedagogía en Historia.

La situación descrita anteriormente se acentúa al abordar el tema de la lectura de textos multimodales publicitarios. Los resultados del estudio indican que mayoritariamente los estudiantes de Pedagogía estiman que el objetivo central de la publicidad es informar acerca de 
productos o servicios que se ofrecen en el mercado. Si bien reconocen el componente persuasivo de la publicidad, un número significativo de estudiantes considera que la publicidad es un instrumento que aporta información objetiva de los productos que se promocionan, lo que revela una visión alterada respecto de la comprensión del fenómeno publicitario y sus finalidades persuasivas que buscan modificar comportamientos en los eventuales consumidores. Con esto se desconocen algunos planteamientos relevantes ofrecidos por la semiótica social como, por ejemplo, el hecho de que la relación entre significado y significante en el discurso mediático es absolutamente motivada por los intereses ideológicos de quienes producen y difunden esos discursos (Kress, Leite García, van Leeuwen, 2001). Esto demuestra la necesidad no solo de incorporar el concepto de lectura crítica de medios, sino derechamente el de alfabetización visual crítica (Araya y Farías, 2014). No deja de ser preocupante en el ámbito de la formación de los futuros profesores el que se aprecie esta postura pasiva y acrítica frente a los mensajes publicitarios (Del Valle et al., 2012) sobre todo en los estudiantes de pedagogía en Matemática quienes muestran resultados que alcanzan un nivel de análisis -según estudios internacionales (Calvert, 2008; Pécora et al., cit. en Del Valle et al., 2012) - equivalente a los ocho años de edad.

En la línea de la formación de los estudiantes en la escuela, una investigación denominada Análisis descriptivo de textos escolares de Lenguaje y Comunicación (Pereira y González, 2011) arroja resultados relevantes en cuanto a los engranajes semióticos que se articulan en dichos textos y cómo los recursos de producción de significado dialogan entre sí. En este estudio se aplica el modelo MADETEC (Modelo de análisis descriptivo de textos escolares) que está conformado por cinco componentes que permiten enfrentar el material didáctico: estructural, identificatorio, genérico, icónico y diseño. Estos componentes se focalizan en distintos aspectos del texto escolar y el corpus examinado corresponde a dos textos de $5^{\circ}$ y $6^{\circ}$ básico del sector Lenguaje y Comunicación.

Dentro de las conclusiones relevantes de la aplicación del modelo mencionado, se puede destacar el que constituye una valiosa guía de análisis de textos multimodales, puesto que recoge diversos aspectos de la configuración del texto y muestra de qué forma los elementos que conforman la estructura multimodal pueden ser asociados para otorgar significados mucho más completos. Desde la perspectiva de la formación 
de los estudiantes, el análisis efectuado indica que en general las imágenes cumplen más bien una función ornamental, estética e incluso motivacional, lo cual evidencia un escaso tratamiento interpretativo y, además, va en la línea contraria de uno de los supuestos básicos que fundan el estudio, esto es que las imágenes no debieran ser relegadas a un plano secundario sino ser consideradas como poseedoras de significado, equivalente a los significados que se canalizan mediante el texto escrito convencional. Lo anterior ciertamente es relevante, pues el estudio señala que las imágenes son portadoras de significados autónomos que no son explicitados a través del texto verbal.

Esto último resulta particularmente llamativo porque -como señalan los autores- al aplicar el aparato teórico que ofrece el modelo se advierte que en rigor las imágenes sí cumplen una función complementaria e informativa lo cual deja de manifiesto el escaso provecho que se obtiene de una lectura que debiera ser integrada. Al parecer-se concluye- es más importante el aporte estético de las imágenes y no el análisis comprensivo de los distintos modos semióticos.

Los resultados que ofrece el estudio mencionado indican que existen carencias en el ámbito de los procesos de alfabetización visual por parte de los docentes quienes no son capaces de mostrar a los estudiantes la articulación entre los distintos modos de producción de significado, dado que la investigación demuestra que al aplicar el modelo se desprenden variadas funciones de significado que cumplen las imágenes a lo cual claramente no se le saca el debido provecho pedagógico.

Una reflexión y una pregunta que emergen a partir de los antecedentes expuestos es que la formación inicial de profesores en especial en el área de Lenguaje no se ha hecho cargo de la incorporación del componente multimodal que interviene en los procesos de comprensión de lectura, situación que difícilmente se podrá extrapolar a los estudiantes que en el futuro estarán bajo el cargo de estos profesores en formación y así continuaremos reproduciendo esta notable falencia en el ámbito formativo. La pregunta: ¿Qué mejor lugar para empezar a introducir las competencias necesarias en la lectura crítica de textos multimodales que entre quienes tendrán la tarea de educar a las nuevas generaciones?

En el contexto de las recientes búsquedas de modelos educativos que se puedan emular con el fin de mejorar la calidad de la educación en 
Chile, conviene mencionar que el sistema australiano de medición de las habilidades lectoras, NAPLAN (National Assessment Program Literacy and Numeracy) incorpora la dimensión semiótica, lo cual va en paralelo a los avances en investigación de las relaciones entre texto e imagen en textos multimodales (Unsworth, 2006, 2008; Unsworth y Chan, 2009; Unsworth, Thomas y Bush, 2004).

\section{Bases para la caracterización de textos multimodales: estudiantes y profesores. Resultados}

Si se comparan las conclusiones preliminares que se derivan de nuestra investigación sobre las características de los textos de uso cotidiano y en estudios universitarios con los resultados de los estudios precedentes en relación con la lectura en distintos soportes, emergen ideas ciertamente relevantes que continúan en la misma línea de reflexión.

\section{1. Encuesta a estudiantes}

Los resultados de la encuesta aplicada a 61 estudiantes de una universidad tradicional y dos privadas se procesaron en una base de datos que permitió observar las siguientes recurrencias y agrupaciones semánticas en las respuestas (los números entre paréntesis indican la frecuencia de la palabra al aplicar la función Word List del programa AntConc). Las columnas numeradas de 1 a 7 corresponden a las preguntas del Cuestionario de Diagnóstico de Textos aplicado. Las respuestas de las otras 3 preguntas se integraron en la discusión dado que correspondían a frecuencia de uso de blogs, páginas web y portales. 
Tabla 1. Resultados globales del Cuestionario de Diagnóstico de Textos por preguntas.

\begin{tabular}{|c|c|c|c|c|c|c|}
\hline $\begin{array}{l}\text { 1. Ultima } \\
\text { lectura }\end{array}$ & $\begin{array}{l}\text { 2.Textos vida } \\
\text { cotidiana }\end{array}$ & $\begin{array}{l}\text { 3.Textos } \\
\text { estudios } \\
\text { universitarios }\end{array}$ & $\begin{array}{l}\text { 4.Características } \\
\text { Textos uso } \\
\text { universidad }\end{array}$ & $\begin{array}{l}\text { 5.Porcentaje } \\
\text { soporte papel } \\
\text { vs en pantalla }\end{array}$ & 6.Imágenes & 7.Sitios \\
\hline $\begin{array}{l}\text { Novelas (59), } \\
\text { Benito Cereno } \\
\text { (17), } \\
\text { Dostoyesvski } \\
\text { (El Príncipe } \\
\text { Idiota) (12), } \\
\text { Textos (12), } \\
\text { Poesía (10) }\end{array}$ & $\begin{array}{l}\text { Novelas (60), } \\
\text { textos (23), } \\
\text { cuentos (18), } \\
\text { revistas (12), } \\
\text { ensayos (10) }\end{array}$ & $\begin{array}{l}\text { Novelas (61), } \\
\text { textos (54), } \\
\text { ensayos (24), } \\
\text { cuentos (21), } \\
\text { poesía (20), } \\
\text { literatura } \\
\text { (21), } \\
\text { lingüística } \\
\text { (19). }\end{array}$ & $\begin{array}{l}\text { Impresos (39), } \\
\text { digitales (33), } \\
\text { verbales (33) } \\
\text { y visuales } \\
\text { (22) }\end{array}$ & $\begin{array}{l}\text { Papel } 69,7 \% \\
\text { Pantalla } \\
30,3 \%\end{array}$ & $\begin{array}{l}\text { Ninguno (20), } \\
\text { ambos (15), } \\
\text { impresos (7), } \\
\text { pantalla (7) }\end{array}$ & $\begin{array}{l}\text { Educarchile } \\
\text { (8), } \\
\text { ciudadseva } \\
\text { (7), scielo.cl } \\
\text { (7), Moodle } \\
\text { (7), Wikipedia } \\
\text { (7), sitios con } \\
\text { dominio cl. } \\
\text { (38) }\end{array}$ \\
\hline
\end{tabular}

Los resultados en la Tabla 1 indican, con respecto a la Pregunta 1, que el último texto leído corresponde a uno literario, novela; dependiendo de la universidad, dos son los mayoritariamente mencionados: Benito Cereno, de Herman Melville y El Príncipe Idiota, de Dostoyevski; luego mencionan textos de distintos tipos: literarios, de estudio, lingüísticos, y, por último, poesía. En cuanto a la Pregunta 2 sobre los textos que leen en su vida cotidiana, fuera de la universidad, mencionan las novelas, nuevamente textos literarios, lingüísticos, históricos y, aunque de parte de un solo estudiante, textos multimodales. Le siguen cuentos, revistas y ensayos. La Pregunta 3 sobre los textos usados en los estudios universitarios la responden mencionando que corresponden a novelas, textos, ensayos, cuentos, poesía, literatura y lingüística. Al referirse a las características de los textos de uso en los estudios universitarios, Pregunta 4, responden que son impresos, digitales, verbales y visuales. En cuanto al soporte textual, Pregunta 5, los estudiantes optan por leer en papel en un promedio de $69,7 \%$ y en pantalla en un 30,3\%. Conviene resaltar que se advierte un solo caso de lectura en pantalla con un $99 \%$ y nueve casos de un 100\% de lectura en papel. A la Pregunta 6 sobre cuáles de los textos en soporte papel y en pantalla contienen imágenes, contestan que ninguno las contiene o que ambos, o que los impresos o los en pantalla. Los sitios que visitan para consultas de estudio, Pregunta 7, son Educarchile, Ciudadseva, Scielo.cl, Moodle y Wikipedia. Hay un alto porcentaje de consultas a sitios con dominio chileno: cl. (38). Por último, una mayoría menciona que tiene cuenta Facebook. 
En perspectiva global, los estudiantes consultados leen de manera mayoritaria textos tradicionales, aunque reconocen que para sus estudios universitarios alternan la lectura de textos lingüísticos y textos visuales. Para este grupo, la novela parece ser el género discursivo de lectura tanto en contextos de la vida personal como en la universitaria, lo que demuestra una dedicación lectora centrada en los estudios. A pesar de que no aparece dentro de los conceptos con mayor recurrencia, algunos estudiantes mencionan educación como uno de los temas que los textos o ensayos abordan, lo cual da cuenta del tercer pilar tradicional en la formación de educadores en Lenguaje y Comunicación, junto a literatura y lingüística. En concordancia con Peronard (2007), se constata que para la vida lectora universitaria los textos impresos tienen preponderancia, seguidos de digitales, verbales y visuales. Conviene destacar que los estudiantes se refieren a verbales ya sea a la grabación de una clase como al sonido de los videos afines a las materias tratadas que ellos y ellas consultan de forma independiente.

En el caso de los estudiantes de la universidad tradicional, la caracterización de los textos es más heterogénea pues identifican en los textos usados para sus estudios una amplia gama de recursos semióticos que los conforman. Al parecer, si lo comparamos con la caracterización de los textos empleados por los estudiantes de las universidades privadas, los estudiantes de la tradicional poseen una mayor conciencia semiótica; aunque se advierte un leve predominio de la lectura de textos impresos escritos. Por su parte, al igual que en los estudiantes de las universidades privadas, los estudiantes de la tradicional prefieren textos impresos, reconocen la ausencia de imágenes en ellos de forma mayoritaria y usan la plataforma moodle de manera frecuente en la mayoría de los casos. Además reconocen que no acceden a blogs, pero sí de forma abrumadora a Facebook.

Por su parte, si observamos los antecedentes entregados por los estudiantes de universidades privadas, se puede advertir que caracterizan de forma diversa los textos que emplean para sus estudios y en algunos casos están conscientes del componente multimodal de ellos, aunque como en el resto de los estudiantes, prefieren la lectura de textos impresos, con excepción del caso bien específico que señalamos. Además tienden a asociar la aparición de las imágenes con la lectura en pantalla y mayoritariamente acceden a sitios y portales web para consultar aspectos 
propios de sus estudios. El acceso a estos sitios es variado en términos de frecuencia, aunque llama la atención que muchos responden que ingresan para resolver dudas puntuales; sin embargo, el acceso parece ser frecuente. Algunos estudiantes consultan diversos blogs y páginas web y, por último, todos los encuestados tienen Facebook.

En general, se puede advertir que los estudiantes de Pedagogía en Lenguaje y Comunicación son tradicionales en relación con los textos que emplean para sus estudios, pues destacan las lecturas de textos impresos, escritos y sin imágenes, de lo que se podría inferir que la formación inicial docente no se ha hecho cargo de forma sustancial del cambio en el paradigma textual lo que se explica por la escasa conciencia de los estudiantes de la configuración semiótica de los textos. Si bien los textos son caracterizados de forma muy diversa, muy pocos identifican la articulación multimodal de ellos. Los procesos de alfabetización al parecer siguen anclados a los textos elaborados a partir del lenguaje en soporte impreso de forma mayoritaria y aparentemente los estudiantes emplean y acceden a los textos multimodales solo por el impulso del contexto social y cultural y no por la inducción de su formación profesional.

Dado este panorama, habría que contrastar estos antecedentes con otros datos proporcionados por quienes ejercen la docencia en la carrera aludida para determinar con qué tipos de textos concretamente se trabaja en diversas fases en la formación pedagógica.

\subsection{Encuesta a formadores: ¿textos multimodales en la formación inicial docente?}

Otro de los aspectos que incorpora esta investigación y que complementa los antecedentes ya señalados en cuanto al proceso lector y las características de los textos, tiene relación con los textos empleados por profesores metodólogos en el proceso enseñanza aprendizaje de la comprensión de lectura y la relevancia que a ésta se le asigna en la formación inicial de los estudiantes de Pedagogía en Lenguaje y Comunicación.

En esta parte del estudio se aplicó una encuesta abierta y semidirigida a 5 académicos que ejercen la docencia en el área de didáctica y metodología disciplinaria, de dos universidades tradicionales y dos privadas; a partir de la cual se obtuvieron interesantes antecedentes 
respecto a cómo están diseñados los programas académicos y cuáles son los énfasis que se destacan en el trabajo de aula con diversos tipos de textos. El cuestionario recoge diversos datos que apuntan a los objetivos de la investigación:

a) ¿Cuál es la relevancia de las habilidades lectoras en su asignatura?

b) ¿Cuáles son las características de los textos que emplea para la enseñanza de la comprensión de lectura?

c) ¿Cómo aborda la enseñanza de la comprensión lectora en su asignatura? Refiérase a las estrategias o modelos empleados.

d) ¿Qué referencias tiene de los textos multimodales y su importancia en el mundo de hoy?

e) En el proceso de "enseñar a enseñar" comprensión de lectura ¿utiliza textos multimodales?

Las respuestas fueron procesadas con el programa AntConc y los resultados se presentan en la Tabla 2 donde cada columna corresponde a una pregunta y el número entre paréntesis indica la frecuencia de la palabra en la función Word List.

Tabla 2. Resultados globales de la encuesta a metodólogos.

\begin{tabular}{lllll}
\hline $\begin{array}{l}\text { a)Relevancia } \\
\text { habilidades } \\
\text { lectoras }\end{array}$ & $\begin{array}{l}\text { b)Características } \\
\text { textos }\end{array}$ & $\begin{array}{l}\text { c)Didáctica } \\
\text { comprensión } \\
\text { lectora }\end{array}$ & $\begin{array}{l}\text { d)Importancia } \\
\text { de textos } \\
\text { multimodales }\end{array}$ & $\begin{array}{l}\text { e)Uso de textos } \\
\text { multimodales }\end{array}$ \\
\hline $\begin{array}{l}\text { Generar } \\
\text { instrumentos }\end{array}$ & $\begin{array}{l}\text { Textos (16) } \\
\text { Artículos (4) }\end{array}$ & $\begin{array}{l}\text { Enseñanza (7) } \\
\text { Estrategias (7) }\end{array}$ & $\begin{array}{l}\text { Texto } \\
\text { multimodal(4) }\end{array}$ & $\begin{array}{l}\text { Sí utilizo (2) } \\
\text { evalilizo poco (1) }\end{array}$ \\
$\begin{array}{l}\text { Habilidades (7) } \\
\text { lectoras y sentido } \\
\text { crítico (5) }\end{array}$ & & & Lectura (4) & No utilizo (2) \\
Libro-álbum (4)
\end{tabular}


En el caso de la pregunta a) la apreciación global de los académicos difiere en cuanto a las razones o fundamentos de la relevancia de las habilidades lectoras. Las argumentaciones van desde la necesidad didáctica pedagógica de generar instrumentos y pautas de evaluación de la lectura a la capacidad de fomentar las habilidades lectoras y, por su medio, el sentido crítico en la lectura.

Otra respuesta, individual, sostiene que la relevancia de la habilidad lectora está amparada en la orientación que ofrecen los planes y programas de estudio, en los que la comprensión de lectura y el hábito lector constituyen uno de los ejes; que la importancia de la comprensión de lectura está anclada a la necesidad de despertar el pensamiento analítico y crítico de los estudiantes y que la relevancia de la comprensión lectora radica en la comprensión del conocimiento propio de la asignatura puntualmente. En otra respuesta se aborda la pregunta de forma más global al señalar que la importancia de la comprensión lectora está relacionada con el déficit más o menos generalizado evidenciado a partir de estudios en el ámbito de la comprensión de textos por parte de los ciudadanos. Su mirada es más global y da cuenta de la importancia de esta habilidad en la dimensión sociopolítica del progreso de la ciudadanía.

Estas apreciaciones -como se puede observar- apuntan a distintos flancos que debiera cubrir -creemos- la enseñanza aprendizaje de la comprensión lectora.

En relación con la pregunta b) que se refiere a las características de los textos empleados en la enseñanza de la comprensión lectora, las respuestas se aglutinan en torno al concepto de texto, mayoritariamente referido a la importancia de considerar sus tipos y características propias. Una segunda recurrencia refiere a artículos tanto de prensa como de investigación que informen sobre los desafíos del proceso lector.

Una respuesta apunta en primera instancia a los criterios de la comprensión en el contexto de las pruebas estandarizadas como PISA o SIMCE, en las que se incluye un amplio abanico textual que va desde la articulación tradicionalmente verbal hasta los textos multimodales como noticias y cómics. Otra respuesta indica que seincorporan preferentemente artículos o capítulos de libros que formulan planteamientos acerca de las estrategias de comprensión de lectura y, en el ámbito de la generación de material didáctico por parte de los estudiantes, da cabida a una mayor 
variedad textual en la que se incluyen los textos multimodales. Otro de los encuestados indica que se da preferencia a textos altamente connotativos, que denomina pluri significativos, y en los que se puede evidenciar originalidad creativa. Creemos que se trata de textos fundamentalmente literarios. El informante que plantea esto último no menciona los textos multimodales.

Otro informante solo menciona como característica el componente didáctico anclado al concepto actual de habilidad lingüística de leer. $\mathrm{Al}$ igual que en el caso anterior, no se advierten referencias a los textos multimodales.

Cabe destacar que en esta pregunta una informante entrega una amplia mirada en cuanto a las características de los textos que emplea para abordar la habilidad de comprensión de textos, aunque circunscritos al ámbito monomodal. La académica declara que emplea artículos de investigación que dan cuenta de resultados en el ámbito de la comprensión de textos, fuentes del MINEDUC como textos de estudio y análisis de planes y programas. Todo ello abordado desde las competencias, pues -según ella- ese enfoque está vigente en la formación inicial docente.

En cuanto a la pregunta c) las respuestas se aglutinan en torno a dos conceptos: enseñanza y estrategias. Por una parte se refieren a la importancia de la enseñanza de estrategias que potencien el desempeño lector y, por otra, a la necesidad de definir y contextualizar estas estrategias de acuerdo a la jerarquización de ideas, conocimiento previo y secuencia que el texto requiere. Un informante sostiene que el abordaje de la comprensión lectora parte de un diagnóstico desde textos de uso común en el ámbito universitario. Se centra en las habilidades más débiles, trabajando la jerarquización de ideas y la síntesis global desde donde se explicitan los mecanismos de metacomprensión.

Otra respuesta se orienta ala necesidad de análisis de textos teóricos simples que abordan estrategias de activación del conocimiento previo, contextualización, síntesis de información y esquematización. Además, menciona el método de enseñanza recíproca de Brown y Palincsar que consiste en la interrupción de la lectura de un texto cada cierto tiempo para aplicar estrategias tales como aclarar, resumir, preguntar y anticipar.

Otro informante declara que no aborda estrategias didácticas, solo implícitamente trabaja con el reconocimiento de macro y micro estructuras 
y la contextualización sociocultural e histórica de textos literarios. Mientras que otro metodólogo sostiene que aborda la comprensión de lectura desde el enfoque comunicativo funcional y desde la perspectiva lingüística y cognitivo constructivista anclado a la didáctica.

En otra respuesta se entrega de forma pormenorizada antecedentes relevantes del trabajo en el desarrollo de la comprensión lectora. Primero, declara que se analizan enfoques respecto de cómo se está trabajando la comprensión de lectura en la actualidad para luego diseñar actividades que permitan aplicar estrategias centradas en el contexto chileno. A continuación, desde las taxonomías, se construyen instrumentos como guías que luego evalúan de forma socializada. Menciona el modelo de Solé que se sostiene en el antes, durante y después de la lectura. Se trabaja además con el concepto de libro-álbum y de aula socrática y la creación de webquests.

En la pregunta d) que apunta a conocer el estatus del texto multimodal en el marco conceptual de los metodólogos, las respuestas se concentran en dos informantes que reconocen la importancia del texto multimodal para sus estudiantes y la necesidad de incorporarlo en la asignatura. Un académico sostiene que los textos multimodales son claves dado que en el diálogo entre escritura e imágenes, estas son fundamentales para entender lo escrito. Este informante declara que en las carreras humanistas donde enseña resulta significativa la relación entre escritura y oralidad en contextos interculturales.

Otro informante reconoce también la importancia de los textos multimodales hoy dado el frecuente contacto de los estudiantes con ellos. Indica que las imágenes han ido desplazando a la palabra como articuladora de significados y por ello se dedica tiempo a la lectura y análisis de publicidad y cortometrajes. Junto con lo anterior, otro académico reconoce la importancia de los textos multimodales dada la integración de texto, imagen y sonido y a partir de estos soportes, declara que pone énfasis en el tratamiento de las ideologías implícitas, los estereotipos sociales, los prejuicios y las visiones de mundo.

Uno de los académicos encuestados admite que no ha incorporado la dimensión multimodal a su enseñanza. Mientras que otro indica que la relevancia de los textos multimodales hoy radica en que quienes ejercerán la docencia están en permanente contacto con ellos y por eso deben ser 
incorporados al aula, pues -especula- ayudaría a la comprensión de textos más complejos. Reconoce además que es un nuevo vehículo para acceder a la cultura.

En cuanto al uso de los textos multimodales en el proceso de "enseñar a enseñar" la comprensión de lectura (pregunta e) las respuestas indican que dos informantes sí los usan en tanto otros dos no los usan y uno hace poco uso de ellos. En una respuesta se señala que se utiliza solo centrándose en las relaciones entre escritura y visualidad, dejando de lado los aspectos sonoros, para lo cual emplea libro-álbum, novelas gráficas y cómics. Por su parte, otro académico declara que se usan poco aunque reconoce su relevancia. Otro dice que los emplea pero sin agregar mayores antecedentes. Mientras que otro informante integra el libroálbum, los book-trailers y el cine dentro del aula, para desde su análisis construir secuencias didácticas.

Las respuestas de estos formadores de docentes evidencian la tenue transición hacia la comprensión del texto multimodal y su integración en el componente de lectura. Si bien se constata algún grado de reconocimiento de la dimensión sociosemiótica que articula los textos multimodales, algunos de estos formadores privilegian el texto escrito literario por sobre la variedad de tipos de textos a los que se enfrentan tanto los estudiantes en formación inicial docente como sus futuros estudiantes. Conviene también reconocer que para la nueva generación de formadores el concepto de multimodalidad no les es ajeno.

\section{Discusión y conclusiones}

Las voces de estudiantes y formadores de docentes en Lenguaje y Comunicación indican que podría existir una transición en el abordaje de los procesos de lectura donde se reconoce la participación cada vez más creciente de textos multimodales. Se constata una tensión entre procesos lectores anclados en textos impresos de naturaleza literaria y lecturas más amplias que incorporan el texto multimodal.

Otro aspecto que salta a la vista es el hecho de que si bien el discurso multimodal está siendo incorporado progresivamente en el aula, las pruebas estandarizadas no lo recogen de forma sistemática lo cual genera un notorio desajuste entre los intentos que se realizan en aula por no solo incorporar dichos textos sino también analizarlos, y la orientación y los 
énfasis didácticos que se pueden estar produciendo en los últimos niveles de la etapa de formación escolar que van dirigidos a la preparación de la PSU, instrumento que en general ha privilegiado la comprensión de textos articulados fundamentalmente a través de la lengua.

Delos antecedentes proporcionados por ambos grupos deinformantes, se podría sostener que el factor generacional parece ser gravitante en la inclusión de los textos multimodales en los procesos de enseñanza aprendizaje de la comprensión de lectura. Los estudiantes de Pedagogía en Lenguaje y Comunicación están siendo instruidos, mayoritariamente, por profesores que construyeron sus carreras y desempeño profesional sobre la base del trabajo con textos lingüísticos tradicionales y ese mismo aspecto formativo ha orientado también el camino pedagógico de los estudiantes. Si bien éstos acceden y en alguna medida tienen conciencia de los textos multimodales y su configuración semiótica, no lo hacen desde la inducción didáctica y pedagógica, sino por el influjo del contexto sociocultural marcado por nuevas plataformas textuales.

Aventuramos otra posible explicación que marca el tránsito de la lectura en papel y centrada en el código lingüístico a la lectura multimodal: los modelos descriptivos de la lengua siguen -filológicamente- anclados en el nivel oracional, con escasos gestos al nivel textual y ausencia de la dimensión sociosemiótica que constituye los textos.

En relación con las preguntas formuladas al comienzo de este trabajo, podemos señalar que el uso de los textos multimodales por parte de los estudiantes parece ser variado y no está circunscrito necesariamente al ámbito académico. Parece ser que el texto multimodal no reviste relevancia académica para los estudiantes y esto podría explicarse por el hecho de que en sus procesos formativos este texto no ha logrado validarse como una fuente de conocimiento. Hay que recordar lo que menciona Zamora (2006) en cuanto a que la mirada iconocéntrica no ha permeado al ámbito académico, el que sigue enfatizando la dimensión logocéntrica.

En cuando al tratamiento que se le da al texto multimodal por parte de los profesores metodólogos en la formación inicial docente, podemos indicar que se advierte una escasa inclusión dentro de sus diseños pedagógicos. Los procesos de enseñanza aprendizaje de la comprensión de lectura aún permanecen ligados al texto articulado a 
través de la lengua, aunque los profesores reconocen la relevancia del texto multimodal en el paisaje semiótico actual.

Los resultados parecen ratificar algunas de las conclusiones planteadas por Villa (2008) en cuanto a que los docentes no han sido formados conceptualmente para valorar la imagen en los procesos de comprensión de lectura, a lo cual se agrega la precariedad de recursos didácticos que guíen la tarea de enseñar a leer textos multimodales. Esta falta de atención a las imágenes y a los sistemas visuales de significado representa serios desafíos a los profesores en tiempos cuando la imagen ha comenzado a dominar la vida de nuestros estudiantes (Kress, 2003).

No podemos dejar de mencionar que otro posible factor de la renuencia en la formación docente por aceptar los textos multimodales y la comunicación mediada por el computador puede ser la actitud hacia la lengua cibernética o ciberlecto, como lo señala la siguiente cita:

En la casa común de las nuevas tecnologías globalizadoras va a ser fundamentalmente la lengua el depositario esencial de nuestra identidad. Y esto debiera estimular a volver la mirada al idioma: a velar por su defensa debido a su capacidad para actuar como garante de las señas de identidad de una comunidad, y por tanto de su capacidad para definir un ámbito de solidaridad" (Ávila, 2006: 47)

Esta actitud puede también obedecer a diferencias generacionales, donde escuchamos menos problemas "tecnofóbicos" en las generaciones de nativos digitales que en la de inmigrantes digitales (Prensky, 2001).

El conocimiento que hemos co-construido a partir de las voces de la literatura reseñada y de los estudiantes y profesores en programas de formación inicial docente que constituyen la muestra de este estudio, nos permiten sugerir acercamientos más efectivos que integren y validen al texto multimodal en la evaluación de la comprensión lectora. Apelando a la metáfora de "el mapa y el territorio", vemos que las comunidades discursivas de hoy constituyen un territorio de cambiante topografía y morfología donde la multimodalidad forma parte importante del paisaje; en tanto, la formación inicial docente y el tratamiento pedagógico de la lectura se guían por mapas que no dan cuenta del tal territorio. 


\section{Bibliografía}

Araya, C. y Farías, M. (2014). Alfabetización visual crítica y educación en lengua materna: estrategias metacognitivas en la comprensión lectora de textos multimodales. Colombian Applied Linguistics Journal, 16(1), 93104. doi: dx.doi.org/10.14483/udistrital.jour. calj.2014.1.a08

Ávila, R. (2006). De la imprenta a internet: lengua española y los medios de comunicación masiva. México, DF: El Colegio de México.

Barragán, R. y Gómez, W. (2012). El lenguaje de la imagen y el desarrollo de la actitud crítica en el aula: propuesta didáctica para la lectura de signos visuales, IKALA. Revista de lenguaje y cultura, 17(1), 81-93.

Buckingham, D. (2008). Media education. Cambridge: Polity Press.

Cassany, D. (2005). Investigaciones y propuestas sobre literacidad actual: multiliteracidad, internet y criticidad. Cátedra UNESCO para la Lectura y la Escritura. Concepción: Universidad de Concepción. Recuperado de http: / / www2.udec.cl/catedraunesco/05CASSANY.pdf

Del Valle, C.,Denegri, M. y Chávez, D. (2012).Alfabetización audiovisual y consumo de medios y publicidad en universitarios de Pedagogía en Chile. Comunicar, 19(38), 183-191.

Hall, C., Smith, P. y Wicaksono, R. (2011). Mapping applied linguistics. A guide for students and practicioners. Londres: Routledge.

Kress, G. R. y van Leeuwen, T. (2001). Multimodal discourse: The modes and media of contemporary communication. London: Edward Arnold.

Kress, G; Leite-García, R. y van Leeuwen, T. (2001). Semiótica discursiva. En Van Dijk (Comp). El Discurso como estructura y proceso (pp.373-416). Barcelona: Gedisa. 
Kress, G. R. (2003). Literacy in the new media age. New York: Routledge

Luke, C. (2000). New literacies in teacher education. Journal of Adolescent $\mathcal{E}$ Adult Literacy, 43(5), 424-435.

Pereira, F. y González, G. (2011).Análisis descriptivo de textos escolares de Lenguaje y Comunicación. Literatura y Lingüística, 24, 161-182.

Peronard, M. (2007). Lectura en papel y en pantalla de computador. Revista Signos, 63(40), 179-195.

Prensky, M. (2001). Digital natives, digital inmigrants. On the Horizon, 5(9), 1-6.

Serafini, F. (2011). Expanding perspectives for comprehending visual images in multimodal texts. Journal of Adolescent $\mathcal{E}$ Adult Literacy, 5(54), 342-350.

Turkle, S. (1995). Life on the screen: identity in the age of Internet. New York: Simon and Schuster.

Unsworth, L., Thomas, A. y Bush, R. (2004). The role of images and imagetext relations in group 'Basic Skills Tests' of literacy for children in the primary school years. Australian Journal of Language and Literacy, 1(27), 46-65.

Unsworth, L. (2006). Towards a metalanguage for multiliteracies education: Describing the meaning-making resources of language-image interaction. English Teaching: Practice and Critique, 1(5), 55-76.

Unsworth, L. (2008). Multiliteracies and metalanguage: describing image/text relations as a resource for negotiating multimodal texts, in Coiro, J. et al (eds). Handbook of research on new literacies (pp. , 377-405). New York: Lawrence Earlbaum.

Unsworth, L. y Chan, E. (2009).Bridging multimodal literacies and national assessment programs in literacy. Australian Journal of Language and Literacy, 3(32), 245-257.

Villa, N. (2008). Propuesta de alfabetización visual para estudiantes de educación básica apoyada en recursos 
hipermediales. Un aporte a la comprensión lectora. Revista Interamericana de Bibliotecología, 1(31), 207225.

Zamora, F. (2006). Filosofía de la imagen. Lenguaje, Imagen y Representación. México, DF: Universidad Autónoma de México. ENAP. 